\title{
AIR FLUID LEVELS ON CHEST RADIOGRAPH: A REVIEW OF TWO CASES OF UNCOMMON ETIOLOGY
}

Namrata Jasani ${ }^{1}$, Himavathy Gara²

\section{HOW TO CITE THIS ARTICLE:}

Namrata Jasani, Himavathy Gara. "Air Fluid Levels on Chest Radiograph: A review of two cases of uncommon Etiology". Journal of Evolution of Medical and Dental Sciences 2014; Vol. 3, Issue 31, July 31; Page: 8614-8619, DOI: $10.14260 /$ jemds/2014/3095

ABSTRACT: AIMS: This paper describes assessment of patients with air fluid levels on chest radiography of uncommon etiology. STUDY DESIGN: A review of literature on air fluid levels on chest radiography is described and differential diagnosis is summarized. The case of a young girl with recurrent episodes of hemoptysis and the case of another woman with breathlessness are presented.

PRESENTATION OF CASES: The patients were admitted through emergency department where they were assessed and treated in a medical intensive care unit with the involvement of internal medicine team. Laboratory work up confirmed the diagnosis of bronchogenic cyst and hydatid cyst. Medical treatment was administered and supportive care was undertaken. Patients were referred to the cardiothoracic surgeon for lobectomy/cystectomy. DISCUSSION: Air fluid levels seen on chest roentgenogram due to many pulmonary like hydropneumothorax, lung abscess, fluid filled cavity, bullae, cyst and some non-pulmonary causes like diaphragmatic hernia. It is important to identify the exact cause as the further management would be dependent on that. CONCLUSIONS: These cases emphasize that practitioners should consider uncommon etiologies in patients with air fluid levels chest radiography.

KEYWORDS: Air fluid levels, Chest Radiography, Hydatid cyst, Brochogenic cyst.

INTRODUCTION: The radiographic assessment of patients with air fluid levels on chest X-ray is a common clinical problem. Hydropneuomothorax and lung abscess usually are the main consideration in patients with these findings. However, many other diseases or abnormalities like fluid filled cavity, bullae, cyst, pulmonary infarction and non-pulmonary causes like diaphragmatic hernia, pancreatitis, hydatid cyst, etc. may also present with air fluid levels on chest radiograph. Some have specific appearances that may suggest the correct diagnosis or limit the differential diagnosis. Failure to recognize and treat the primary underlying cause is associated with a poor clinical outcome. It is, therefore, important for the clinicians to not only recognize the common conditions of air fluid levels but to appreciate the more unusual causes of air fluid levels on chest radiograph that may alter therapy or need surgical intervention.

CASE 1: A young girl of 16years age presented to the outpatient department with history of recurrent episodes of hemoptysis associated with breathlessness on exertion since the age of one year. History was unremarkable and there were no constitutional symptoms like cough, fever, chest pain, weight loss or bleeding manifestations. Physical examination did not reveal any abnormal finding.

The complete blood count, urine analysis, bleeding time, clotting time, prothrombin time and activated partial thromboblastin time were within normal limits. The chest radiograph (Fig. 1) showed the presence of a cystic lesion in the right paracardiac region on the left mid and lower zone with a crescent shaped fluid level within. Pulmonary function tests on presentation were within 
normal limits. The various differential diagnoses considered at this stage included sequestration of lung, cystic malformation and bronchogenic cyst. The chance of lung abscess was very remote in the absence fever and other constitutional symptoms. A CT Aortogram was planned to rule out sequestration.

The CT Aortogram features were suggestive of a lung cyst communicating with a bronchus in the left lower lobe with a tiny AV malformations/aneurysm in its lateral wall supplied by branches from left fifth, sixth, and seventh posterior intercostals arteries, pulmonary artery and vein. (Fig. 2A, 2B and 3).

In view of recurrent hemoptysis, left lower lobectomy was performed and the gross pathological examination showed the presence of a cyst of $5 \mathrm{~cm}$ in diameter around the major bronchus. Histopathology revealed a cyst lined by pseudostratified ciliated epithelium showing smooth muscle suggestive of a benign bronchogenic cyst (Fig. 4).

On follow up, the patient complained of persistant dull aching chest pain at about 4 weeks post operatively. A chest X-ray was done which showed the presence of a radiodense lesion in the retrocardiac region suggesting pleural collection which on CT scan found to be pleural thickening.

CASE 2: A 22years old married female presented to the emergency department history of grade 4 breathlessness and dry cough of 2 days associated with low grade fever and dull aching chest pain. The patient was unwell for the past six months and was complaining of intermittent dull aching chest pain, on and off dry cough and exertional breathlessness.

On physical examination, her pulse rate was 128 beats per minute, blood pressure 120/70 $\mathrm{mm} \mathrm{Hg}$, respiratory rate 38 cycles per minute and SpO2 of 92\% with face mask oxygen of 6 liters per minute. General examination was unremarkable except for the presence of mild pallor. Respiratory system examination revealed reduced breath sounds on the right side with bilateral inspiratory crepitations.

A bedside chest radiograph was done which showed the presence of air fluid level on the right side with mediastinal shift towards left (FIG. 5A). A working diagnosis of right sided hydropneomothorax was made based on the chest radiograph and a lateral view was ordered which did not show the homogenous density posteriorly (Fig 5 B).The hemoglobin was 8.8 gm\%.

As the patient was very sick and was with clinical symptoms of infection, a broad spectrum antibiotics and high flow oxygen was initially started. Once the patient stabilized and her general condition improved, a contrast enhanced computer tomography was done which showed the presence of $9 \times 10 \times 3.2 \mathrm{cms}$ well defined, non-enhancing cystic lesion with air fluid levels suggestive of hydatid cyst with mild pleural effusion on the right side.

Oral albendazole 400mg twice a day was added and the patient was referred to cardiothoracic surgeon for cystectomy.

DISCUSSION: Air fluid levels on the chest X-ray is quite common in clinical practice and diagnosis is not always easy. Many conditions, both pulmonary and non-pulmonary conditions, present as air fluid levels on chest radiography and many of these cause serious diagnostic difficulties. Accurate radiographic interpretation is paramount important as clinical management and radiographic diagnosis are intimately interwoven when dealing with these conditions. 
Our cases illustrate the uncommon etiology of this radiological presentation. Wherein the first case absence of constitutional symptoms with recurrent episodes of hemoptysis posed a diagnostic difficulty and the second case represents how a tropical disease may mislead if not suspected early.

Bronchogenic cysts are congenital lesions arising from the abnormal budding of the ventral foregut that occurs between the 26th and 40th days of gestation. ${ }^{1}$ Most of the cysts are located in the mediastinum along the tracheobronchial tree, but they can also be found in the lung parenchyma (15\%-20\%).2,3,4 or may extend to or below the diaphragm as dumb-bell cysts.

It is unusual for them to have a patent connection with the airway, but when present, such a communication may promote infection of the cyst by allowing bacterial entry. According to the literature, most intrapulmonary cysts occur in the lower lobes. They can occur in many atypical locations, ranging from the neck to the spinal dura mater, to below the diaphragm. 4,5,6 Most bronchogenic cysts are symptomatic. The most frequent symptoms are cough, fever, pain, and dyspnea. Tracheobronchial compression and pulmonary infections can occur in children because of the relatively soft tracheobronchial tree.4,6,7

Hydatid cyst disease is a zoonotic disease caused by the larval stage of Echinococcus granulosus (dog tapeworm), E. multilocularis, or E. vogeli. When rupture of the hydatid cyst occurs into the pleural space, complications like hydropneumothorax and empyema may occur.

Radiological studies play a very important role in detecting and evaluating air-fluid levels. Plain X-ray films are not always sufficient to diagnose the etiology of these air fluid levels. Ultrasonography, CT, echocardiography and magnetic resonance imaging (MRI) are of great value in diagnosing and determining the anatomic extent and relationship.

\section{REFERENCES:}

1. Mc Adams HP, Kirejczyk WM, Rosado-de-Christenson ML, Matsumoto S. Bronchogenic cyst: imaging features with clinical and histopathologic correlation. Radiology 2000; 217:441-6

2. St. Georges R, Deslauriers J, Duranceau A, Vaillancourt R, Deschamps C, Beauchamp G, et al. Clinical spectrum of bronchogenic cysts of the mediastinum and lung in the adult. Ann Thorac Surg 1991; 52:6-13.

3. Di Lorenzo M, Collin PP, Vaillancourt R, Duranceau A. Bronchogenic cysts. J Pediatr Surg 1989; 24:988-91.

4. Suen HC, Mathisen DJ, Grillo HC, LeBlanc J, McLoud TC, Moncure AC, Hilgenberg AD. Surgical management and radiological characteristics of bronchogenic cysts. Ann Thorac Surg 1993; 55:476-81.

5. Rapado F, Bennett JD, Stringfellow JM. Bronchogenic cyst: an unusual cause of lump in the neck. J Laryngol Otol 1998:112;893-4.

6. Ramenofsky ML, Leape LL, McCauley RG. Bronchogenic cyst. J Pediatr Surg 1979; 14:219-24.

7. Ribet ME, Copin MC, Gosselin BH. Bronchogenic cysts of the lung. Ann Thorac Surg 1996; 61:1636-40. 


\section{CASE REPORT}

Figure 1: showing a cystic lesion in the left paracardiac with a crescent shaped fluid level.

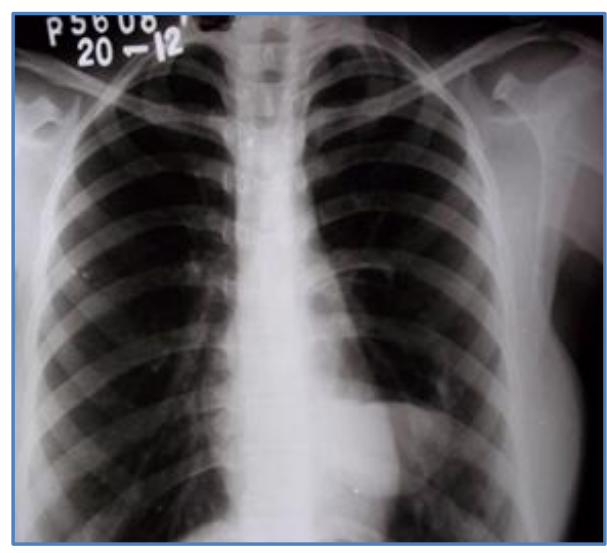

Figure 1

Figure 2: CT Thorax showing lung cyst.
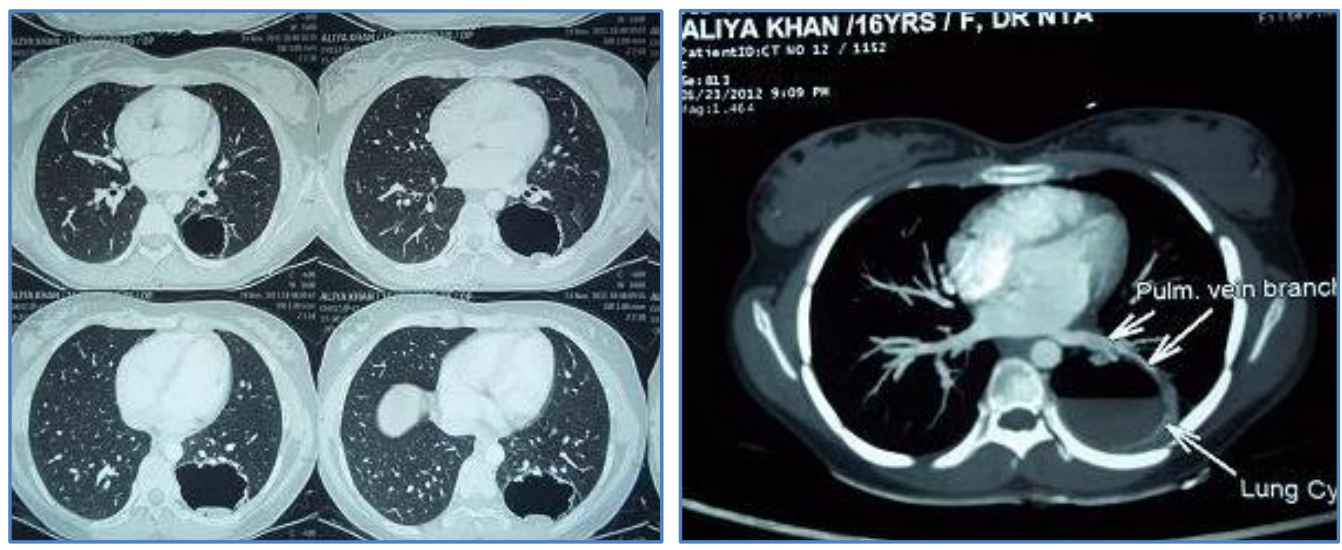

Figure 2

Figure 3: CT Aortogram.

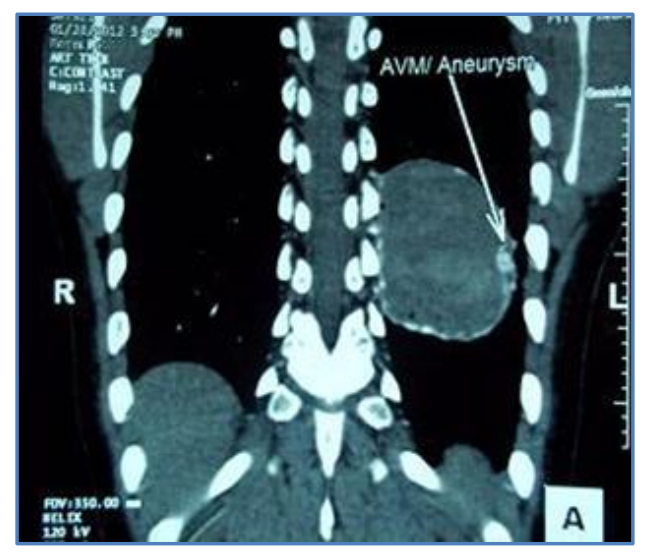

Figure 3 


\section{CASE REPORT}

Figure 4: Gross appearance of the cyst.

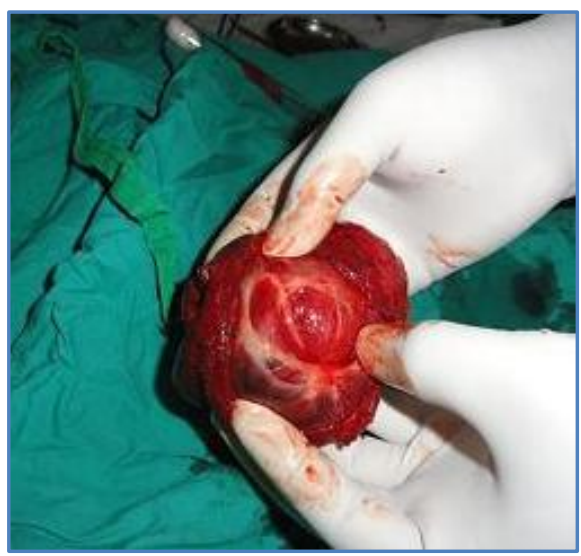

Figure 4

Figure 5: A) Chest $\mathrm{X}$ ray showing air fluid level on the right side with shift of mediastinum towards left. B) Lateral View.

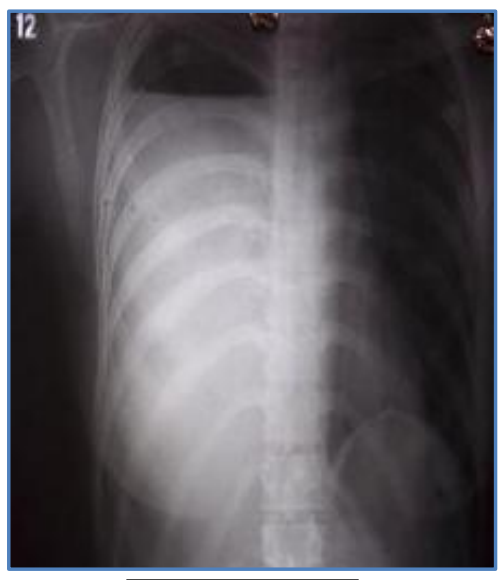

Figure 5A

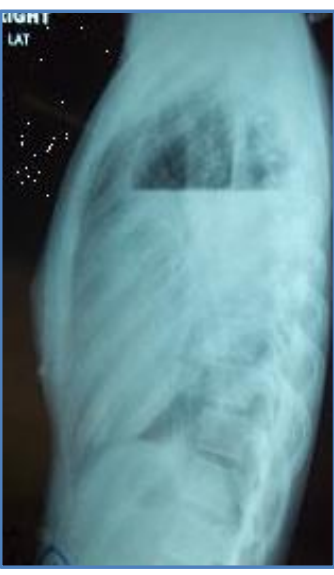

Figure 5B

Figure 6: CT Thorax showing lung cyst- (A) Lung window (B) Aortopulmonary window.

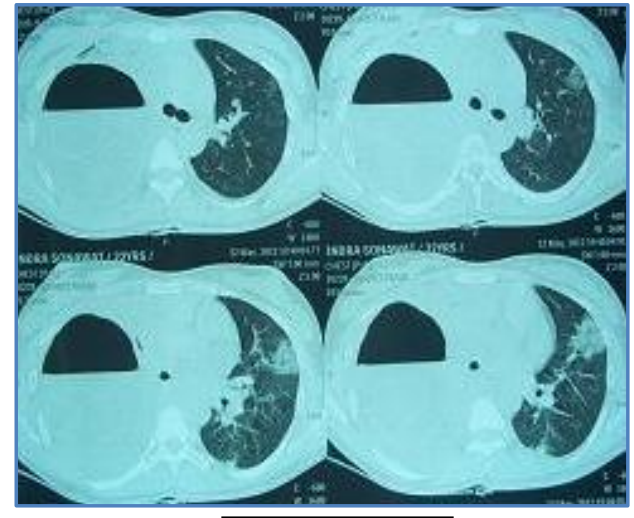

Figure 6A

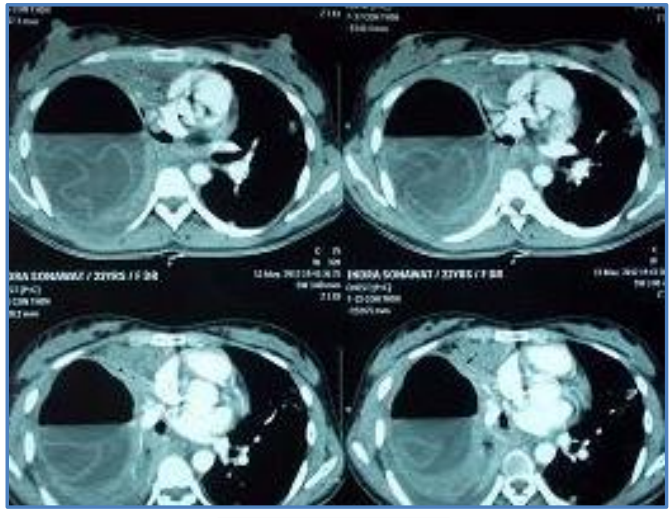

Figure 6B 


\section{CASE REPORT}

\section{AUTHORS:}

1. Namrata Jasani

2. Himavathy Gara

\section{PARTICULARS OF CONTRIBUTORS:}

1. Medical Officer, Department of General Medicine, YCM Hospital Pimpri.

2. Medical Officer, Department of General Medicne, YCM Hospital Pimpri.

\section{NAME ADDRESS EMAIL ID OF THE} CORRESPONDING AUTHOR:

Dr. Namrata Jasani,

124/125, Santvani Tower,

Off Devidas Lane,

L. I. C. Colony, Borivali (W),

Mumbai-40013, Maharashtra.

Email: drnamrata.jasani@gmail.com

Date of Submission: 08/07/2014.

Date of Peer Review: 09/07/2014.

Date of Acceptance: 22/07/2014.

Date of Publishing: 30/07/2014. 